\title{
Information Seeking and Use by Grade 9 Students: More and Less Savvy Than You Might Think
}

\author{
Eric M. Meyers \\ Doctoral Candidate \\ The Information School, University of Washington \\ United States \\ Michael B. Eisenberg \\ Professor and Dean Emeritus \\ The Information School, University of Washington \\ United States
}

\begin{abstract}
This paper presents the findings of a survey administered to 939 high school freshmen (Grade 9, approximately 14 years old) in five schools in the greater Seattle, Washington (USA) area. Responses indicate that students use a wide range of information resources, including books, the Web, and other people, but underutilize subscription databases and periodical literature. Furthermore, there appears to be some confusion over what these databases contain, their utility, and credibility among young people. This paper also introduces a novel survey technique using Personal Response Systems (PRS) for data collection, and suggests that similar researcher-practitioner collaborations can enhance evidence-based practice in teacher-librarianship.
\end{abstract}

Information literacy; information behaviour; secondary schools; survey research

\section{Introduction}

Can we expect secondary students to be able to find a relevant, credible magazine or journal article which supports a given classroom assignment? The answer may surprise you. The structure and content of the Web places an increasing cognitive load on young people, who are thought to lack the skills necessary to make distinctions of authority, currency, objectivity, or accuracy (Agosto, 2002; Bilal, 2001; Fitzgerald, 2005; Williamson, McGregor, Archibald \& Sullivan, 2007). The proliferation of information resources and young peoples' preference for digital media create renewed interest in source selection and credibility assessment, as well as the need for new skills and instructional practices that are rooted in the unique qualities of online interactions.

Competence in the literacies of the information age is critical to being able to participate in a networked world. These competencies include the ability to access, evaluate and use information, as well as manipulate digital technologies and media. Levin and Arafeh (2002) report what they term the "widening digital disconnect" between students and their schools, which includes access to information technologies in education, as well as the capacity of teachers to educate tech-savvy students. Reports suggest that students are increasingly sophisticated in their use of technology; however, this does not mean they are information or media literate.

In order for librarians and educators to successfully prepare students to be effective users of ideas and information, they need to have a firm grasp of what students already know, 
as well as what they do not. This type of contextual knowledge- being aware of what your students can and cannot accomplish prior to instruction-is critical to information literacy interventions. The tendency of the popular press to over- as well as under-estimate the capacities of today's students, the "Google Generation", further creates the opportunity for misconceptions to invade the practice environment (British Library/JISC, 2008). This paper will describe an action research study undertaken to enhance the contextual knowledge of six high school practitioners by surveying a large sample (939 participants) of their incoming $9^{\text {th }}$ grade students. In the process of examining the survey data, this paper will address the following questions:

1. What are emerging trends in students' information seeking and use?

2. How do students perceive the trustworthiness of different types of information?

3. What strategies do students employ when seeking different information sources?

4. How do students perceive the instruction they receive in information seeking and use?

The findings of this study will inform the information literacy instruction efforts of high school educators, and add to the growing body of knowledge on youth information behaviour. This paper also introduces a novel survey technique using Personal Response Systems (PRS) which was found to be reliable as a data collection tool, and particularly engaging for informants. We further hope this project will inspire additional researcherpractitioner engagement, and extend existing efforts to promote evidence-based practice in teacher-librarianship.

\section{Literature Review}

\section{Our Emerging Understanding of the Google Generation Scholar}

Variously referred to in the research literature as the 'Net Generation, Generation Y, Millenials, the Google Generation, and Digital Natives, the students born after 1989 have known of and used the Internet and World Wide Web for most or all of their years in school. As the first groups of these students head to college and university, and the Internet further saturates the educational context, educators are still struggling to understand and adapt to these digital scholars. Sweeny (2006) characterizes these students as impatient, multitasking, highly demanding, experimental and experiential; he suggests that these students have not only different attitudes and expectations toward research, but also different skills and "literacies." Marc Prensky (2001a; 2001b), the technologist who coined the term "Digital Natives," suggests that, as a result of their immersion in interactive, media-rich technologies since birth, “...today's students think and process information fundamentally differently from their predecessors." While this assertion is supported anecdotally by practitioners and in the media (e.g. Isreal 2005; Lippencott 2005; McHale 2005), research to support the proposition of a qualitative difference in student cognition based in longitudinal analysis is lacking, particularly outside the United States.

The British Library's (2008) recent report on the "researchers of the future" looks on these claims with a critical eye. While the report acknowledges that students prefer documents on the Web to print resources, and generally feel comfortable and confident with their use of search engines, it raises the question of whether these are generational attributes, or indications that students are merely early adopters. As the Web has penetrated the 
academy, and more research materials are provided online, the report finds that professors and library practitioners are also adopting the "power browser" style (also referred to as "horizontal information seeking", p. 10) of widely scanning content to satisfy their information needs. Furthermore, the report suggests young peoples' apparent facility with computers "disguises some worrying problems" such as the inability to evaluate information effectively, or use appropriate search strategies (p. 12). Recent studies of U. S. college students and Australian secondary students confirm some of these concerns. Williamson, McGregor, Archibald and Sullivan (2007) report that Australian secondary students are cavalier regarding plagiarism and the authority of sources, and rely extensively on the free Web for information. Gross and Latham (2007) found that college freshman who perform poorly on tests of information literacy tend to overestimate their abilities; that is, students think they are much better information seekers than they really are.

\section{Information Seeking in School}

A growing body of literature has addressed how secondary grade students seek and use information for classroom assignments (Fidel et al. 1999; Gordon 1999; Heinstrom 2006; Herring 2006; Julien 1999; Kuhlthau 1991; Limberg 1999; Todd 1999; Williamson, McGregor, Archibald and Sullivan 2007). These studies find that students encounter significant challenges to resolving their academic information needs. These challenges may be grouped in two broad categories: 1) challenges related to information systems design, specifically information retrieval tools; and 2) challenges related to information seekers' skills and attitudes, including cognitive, metacognitive and affective capacities for addressing information problems. The former category documents students' struggles with search tools, including Web-based search engines and card catalogues, which often do not effectively support student search behaviours and knowledge structures. The latter category includes students' ability to manage search tasks, compose effective search statements, and evaluate information sources for quality and relevance. Nearly all studies of information seeking behaviour at school are qualitative; that is, they engage a small number $(<30)$ of participants to develop rich portraits of localized phenomena, but fail to describe broader trends in student behaviour. Interestingly, these qualitative studies tend to refute the notions put forward by proponents of the Digital Natives hypothesis in emphasizing students' struggles with formal information retrieval systems over the interactive, interpersonal systems with which they appear more facile. This paper looks to expand the body of evidence in youth information

behaviour by adding some quantitative measures to the rich, descriptive work of other scholars in this area.

\section{Method of Empirical Investigation}

The Libraries in Small High Schools Project (funded by the Institute for Museum and Library Services) focused on six high schools undergoing organizational and pedagogical reform in the greater Seattle area. Integrating theoretical work with empirical-practical engagement over a 3-year span, the goals of the project included: 1) developing an understanding of the issues faced by teacher-librarians (TLs) during the reform process; 2) assisting TLs in aligning their practice with the information needs of a changing school; and 3 ) identifying best practices to support adaptation. To address the project goals, the research team elected to use a triangulated, qualitative and quantitative approach, developing a comprehensive perspective of the work life of teacher-librarians, the libraries they work in, and their place in the school community. By systematically collecting data from all six sites using identical instruments, protocols, and time frames, the research team was able to build 
case studies and also perform cross-case analyses. Teaching and learning in a small schools environment requires that the library and librarian provide a rich infrastructure of information skills instruction, reading and literacy advocacy, information and technology services, and resources management. The underlying assumption is that effective library and information services are essential for the successful education of adolescents in small high schools. This paper draws on a portion of the quantitative data set collected during the final year of the project.

\section{Participants}

Six high schools from the greater Seattle area were recruited to participate in this study. The six high schools represent the diversity of the region, including geographic, cultural and socioeconomic groups. Two urban schools, three suburban schools, and one rural school compose the sample (see Table 1 for a summary of descriptive statistics for each school).

Table 1: Descriptive Characteristics of Participating High Schools

\begin{tabular}{|c|c|c|c|c|c|c|}
\hline School & Type & $\begin{array}{c}\text { \# of } \\
\text { Students* }\end{array}$ & $\begin{array}{c}\text { \% Qualify for } \\
\text { Reduced Lunch }\end{array}$ & $\begin{array}{c}\text { \% Transitional } \\
\text { Bilingual }\end{array}$ & $\begin{array}{c}\text { Library } \\
\text { Staff (FTE) }\end{array}$ & $\begin{array}{c}\text { District Size } \\
\text { (\# High Schls) }\end{array}$ \\
\hline A & Rural & 1,660 & $13 \%$ & $.1 \%$ & 3 & 1 \\
\hline B & Suburban & 845 & $48 \%$ & $15 \%$ & 3 & 1 \\
\hline C & Suburban & 2,166 & $45 \%$ & $12 \%$ & 2 & 2 \\
\hline D & Suburban & 1,617 & $20 \%$ & $2 \%$ & 2 & 5 \\
\hline E & Urban & 1,076 & $16 \%$ & $6 \%$ & 1 & 10 \\
\hline F & Urban & 1,361 & $32 \%$ & $12 \%$ & 1 & 10 \\
\hline
\end{tabular}

* Data from Washington OSPI October, 2006

A survey instrument was developed to gain insight into students' information behaviours, their views of the school library, and their use of various media for personal and academic tasks (see Appendix for questions and administration protocol). The final instrument incorporated input from the six participating TLs, and was designed to provide both the TLs and the research team with a rich empirical data set for designing policies and practices. The survey relied on two different types of administration systems - the Personal Response System (PRS) equipment that the project supplied to each school, and an online survey tool, Catalyst $W e b Q$, developed by the University of Washington. The 16 question survey was administered by the TLs at five of the six research sites, and responses were gathered from 939 high school freshman (Grade 9, approximately 14 years old).

\section{Personal Response Systems (PRS) and Online Surveys}

The PRS has a number of advantages which make it a unique data collection tool, and a more secure and confidential device for youth informants. The PRS is a means of gathering survey or focus group responses quickly, easily and anonymously with minimal risk. Wireless infrared devices which resemble a television remote control transmit answers to a receiving unit connected to a personal computer. The entire system is highly portable, easy to setup and use, and adapts to a variety of data gathering instruments. PRS has the ease and convenience of a web survey, but without the need for research sites to supply Internet access or computers. Supplying the technology to perform these data gathering sessions to our informant schools helped ensure uniform and equitable participation and minimized challenges that may have resulted from differences in technological capability and resources. 
By contrast, the Catalyst $W e b Q$ system allowed for survey respondents to be more independent in completing the survey. However, its reliance on Internet access and connectivity proved challenging for some schools. Like the PRS System, the UW Catalyst System also enabled gathering data from students anonymously. Later in this paper we discuss the data gathered using these two systems, and analyze the survey systems in terms of response rates, reliability, and user affordances.

\section{Survey Administration}

TLs were asked to administer the survey to $9^{\text {th }}$ graders at their respective schools in order to implement the survey in a way that was most appropriate to each local school context. After training, TLs administered the survey or instructed teachers in how to conduct the survey. The survey was completed by students during their $9^{\text {th }}$ grade orientation course, advisory periods, or other scheduled visits to the library. Five of our six sites participated in the student survey. The survey provided a rich set of quantitative data to triangulate our earlier findings regarding the information behaviour of students observed in the library. Site \#6 did not participate in the survey due to the departure of the TL at the beginning of the third year of the project (August 2006) when the survey was administered at the other sites. Response rates per school (based on total $9^{\text {th }}$ grade enrolment) ranged from $36 \%$ to $66 \%$. Data was collected from the TLs by the research team and analyzed using SPSS 14.0. The following table reflects survey responses received from the five participating research sites:

Table 2: Descriptive Characteristics of Survey Participants

\begin{tabular}{|c|c|c|c|c|c|c|}
\hline \multirow[t]{2}{*}{ School } & \multirow[t]{2}{*}{ Type } & \multirow{2}{*}{$\begin{array}{c}\# \text { of } 9^{\text {th }} \text { Grade } \\
\text { Students* }\end{array}$} & \multirow{2}{*}{$\begin{array}{c}\text { \# Survey } \\
\text { Participants }\end{array}$} & \multirow[t]{2}{*}{ Percent } & \multicolumn{2}{|c|}{ Students with Internet Access @ Home? } \\
\hline & & & & & Frequency & Percent \\
\hline A & Rural & 413 & 273 & $66 \%$ & 222 & $87 \%$ \\
\hline B & Suburban & 269 & 168 & $62 \%$ & 138 & $86 \%$ \\
\hline $\mathrm{C}$ & Suburban & 542 & 195 & $36 \%$ & 160 & $84 \%$ \\
\hline $\mathrm{D}$ & Suburban & 415 & 159 & $38 \%$ & 107 & $70 \%$ \\
\hline $\mathrm{E}$ & Urban & 404 & 144 & $36 \%$ & 133 & $92 \%$ \\
\hline Total & & & 939 & & 760 & $84 \%$ \\
\hline
\end{tabular}

*Latest available data estimated from Washington OSPI total enrolment, October 2006

\section{Findings}

Results of the survey revealed some interesting findings, some of which push against widely-held conceptions of teenage information seekers. We organize our presentation of the survey data around the research questions:

- What are emerging trends in students' information seeking and use?

- How do students perceive the trustworthiness of different types of information?

- What strategies do students employ when seeking different information sources?

- How do students perceive the instruction they receive in information seeking and use? 


\section{Emerging Trends in Students Information Seeking and Use}

Our survey found that students are online in high numbers and in a wide variety of places. $84 \%$ of students reported accessing the Internet at home; this is higher than recent estimates of nationwide access among young people, but consistent with recent upward trends in access (Levin \& Arefah, 2002, Lippencott, 2005). 100\% of students responding reported accessing the Internet either at a friend's house, school, or the public library. $38.5 \%$ of students responded that the place they were most likely to access the Internet, aside from their own home, is the home of a friend. This suggests that Web surfing for young people is a social affair, and may be intertwined with other social activities that occur in children's rooms and homes. Libraries composed the vast majority of the remaining access, reminding us that both school and public libraries play an important role in providing access to electronic information, both for academic tasks and personal enrichment. Table 3 summarizes these results.

Table 3: Internet access

i. Do you have internet access at home?

\begin{tabular}{lcc}
\hline & Frequency & Percent \\
\hline Yes & 760 & 84.0 \\
\hline No & 145 & 16.0 \\
\hline Total & $\mathbf{9 0 5}$ & $\mathbf{1 0 0 . 0}$ \\
\hline \multicolumn{1}{c}{ ii. Where else are you most likely to access the internet? } & Percent \\
\hline \multicolumn{2}{l}{ Frequency } \\
\hline Friend's house & 359 & 38.5 \\
\hline School & 271 & 29.1 \\
\hline Public library & 189 & 20.3 \\
\hline Other & 113 & 12.1 \\
\hline Total & $\mathbf{9 3 2}$ & $\mathbf{1 0 0 . 0}$ \\
\hline
\end{tabular}

\section{Perceptions of Utility and Trustworthiness of Information Sources}

Students report that they are not entirely blind to issues of information quality and credibility in selecting resources. Rather, they suggest through their survey responses that they are more sceptical and discerning than many adults give them credit for. While $48 \%$ indicated they use the Web most often to finish their homework, only $32 \%$ feel it is the most trustworthy source available to them.

Despite access to a wide variety of information sources and formats, students are still willing to use information resources they do not trust, in part because of convenience and ease of use. This lends further credence to qualitative findings that motivation and "satisficing" are important factors in students' information behaviour. In interviews, teachers report using many of the same resources and strategies that students use, largely due to constraints on time, access, and the perception that the quality of "free web" resources is sufficient for the task at hand (Meyers, in press). 
Periodical literature was reported to be the least useful and least trustworthy choice among five formats. This finding suggests that either students do not distinguish among the various types of magazines and journals, or simply have not been instructed in the value of periodicals for relevant, up-to-date, and reliable information. In discussing these findings with students and educators, it became clear that "magazines" are often stereotyped as less credible and useful for schoolwork because of the "worst cases" salient in the minds of users (e.g. National Enquirer or The Sun instead of Newsweek or The Economist). We also found that using terms such as "periodicals" or "journals" did not seem to dispel this confusion.

Table 4: Use and trust of information sources

i. Which information source do you use most to finish your homework?

\begin{tabular}{|c|c|c|}
\hline & Frequency & Percent \\
\hline Websites & 432 & 48.2 \\
\hline Friends and family & 218 & 24.3 \\
\hline Books & 169 & 18.8 \\
\hline Radio, TV, movies & 55 & 6.1 \\
\hline Magazines or newspapers & 23 & 2.6 \\
\hline Total & 905 & 100.0 \\
\hline \multicolumn{3}{|c|}{ ii. Which information source do you trust the most? } \\
\hline & Frequency & Percent \\
\hline Books & 323 & 36.5 \\
\hline Websites & 281 & 31.8 \\
\hline Friends and family & 129 & 14.6 \\
\hline Radio, TV, movies & 93 & 10.4 \\
\hline Magazines or newspapers & 59 & 6.7 \\
\hline Total & 932 & 100.0 \\
\hline & Frequency & Percent \\
\hline Radio, TV, movies & 301 & 34.8 \\
\hline Websites & 173 & 20.0 \\
\hline Friends and family & 149 & 17.2 \\
\hline Magazines or newspapers & 127 & 14.7 \\
\hline Books & 114 & 13.3 \\
\hline Total & 864 & $\mathbf{1 0 0 . 0}$ \\
\hline
\end{tabular}




\section{Information Seeking Strategies}

While students report they use search engines often, they do not use the Web exclusively. Students report consulting a wide variety of information sources for homework and personal information seeking, including interpersonal sources and mass media. When asked how they go about finding Websites, nearly $80 \%$ reported using a search engine (Google, Yahoo!, MS Live, or similar). This is not a surprising finding. However, we found that the role of library websites and librarian-selected online materials and tools in guiding students was less than our practitioners had hoped.

Although all schools in this survey provided an array of vetted, full-text periodical databases, students did not report using these to find periodical literature. Over $75 \%$ of students report they would search elsewhere for magazines and newspapers, bypassing the library website and periodical databases. It is unclear whether students do not recognize that these databases contain full-text magazine articles, or whether they find other access points to this content easier to use. Either way, students appear to underutilize these databases.

Library websites were infrequently reported as a starting point for information seeking ( $<40 \%$ of book searches, $<11 \%$ of magazine searches, $<4 \%$ of web searches). While the schools in our study used the district, school or library website as the default homepage, our observational data confirm that students often bypassed these starting points and went directly to Google or other search engines. Schools which had particularly well designed library websites fared no better than those without. This result may change with instruction, but the survey results suggest that grade 9 students are not accustomed to using institutional portals to scaffold their information search. The responses to our survey are detailed in the three tables below:

Table 5: Where would you go to find a website?

\begin{tabular}{lcc}
\hline & Frequency & Percent \\
\hline Search engine & 699 & 79.4 \\
\hline Periodical databases & 90 & 10.2 \\
Library website & 34 & 3.9 \\
Other & 57 & 6.5 \\
\hline Total & $\mathbf{8 8 0}$ & $\mathbf{1 0 0 . 0}$
\end{tabular}

Table 6: Where would you go to find a book?

\begin{tabular}{lcc}
\hline & Frequency & Percent \\
\hline Library website & 359 & 38.2 \\
\hline Search engine & 197 & 21.0 \\
Bookstore or newsstand & 145 & 15.4 \\
Amazon.com & 96 & 10.2 \\
Other & 112 & 11.9 \\
\hline Total & $\mathbf{9 0 9}$ & $\mathbf{1 0 0 . 0}$
\end{tabular}


Table 7: Where would you go to find a magazine article?

\begin{tabular}{lcc}
\hline & Frequency & Percent \\
\hline Search engine & 357 & 38.0 \\
\hline Bookstore or newsstand & 184 & 19.6 \\
Periodical databases & 117 & 12.9 \\
\hline Library website & 95 & 10.1 \\
\hline Other & 154 & 16.4 \\
\hline Total & $\mathbf{9 0 7}$ & $\mathbf{1 0 0 . 0}$
\end{tabular}

\section{Students Perceptions of Instruction}

In the final questions of the survey, students were asked to describe the assistance teacher-librarians provide in terms of gaining access to three information sources: websites, books, and magazine articles. The questions were phrased as historical ("has a librarian ever taught you...") to elicit students' perceptions of their instruction, not to assess their actual facility in finding materials, or to document actual instruction patterns. Table 8 illustrates the students' responses to these questions, which were framed as yes/no queries.

Overall, students strongly associated their instruction in finding books (74.2\%) and websites $(60.4 \%)$ with teacher-librarians. Not so with magazine articles: only $28.8 \%$ of students recall having been instructed in finding periodical content. This strong reversal in student perceptions regarding magazine/periodical instruction is particularly striking when combined with findings concerning periodical use and trustworthiness documented above.

\section{Table 8: School librarian instruction}

\section{i. Has a school librarian ever taught you to find a website?}

\begin{tabular}{lcc}
\hline & Frequency & Percent \\
\hline Yes & 479 & 60.4 \\
\hline No & 314 & 39.6 \\
\hline Total & $\mathbf{7 9 3}$ & $\mathbf{1 0 0 . 0}$ \\
\hline \multicolumn{1}{r}{ ii. } & Has a school librarian ever taught you to find a book? & \\
\hline \multicolumn{1}{l}{ Yes } & Frequency & Percent \\
\hline No & 534 & 74.2 \\
\hline Total & 186 & 25.8 \\
\hline \multicolumn{1}{c}{ iii. } & Has a school librarian ever taught you to find a magazine article? & $\mathbf{1 0 0 . 0}$ \\
\hline & Frequency & \\
\hline Yes & 169 & Percent \\
\hline No & 418 & 28.8 \\
\hline Total & $\mathbf{5 8 7}$ & 71.2 \\
\hline
\end{tabular}




\section{Methodological Findings: PRS as a Research Tool}

This paper introduced a unique method of collecting survey data: the personal response system (PRS). While these tools are traditionally used in formative assessment routines in progressive K-20 contexts, particularly post-secondary lecture courses, we found that they may also contribute to the development of evidence-based practice in school libraries. In this case, we also used these devices to gather reliable data for academic research. PRS, relative to other survey administration techniques, may also provide specific benefits in terms of using survey data for action research and evidence-based practice.

Research on survey methods have found online survey administration to provide significant benefits. Online surveys lower costs, provide greater sample sizes, and offer greater convenience to both researchers and participants (Schmitt, 1997). In recent years, online surveys have been acknowledged as valid and reliable techniques for data collection, and furthermore have the added benefit of reducing some self-presentation bias. One of our schools elected to use an online administration, while four others administered the identical instrument using the supplied PRS system. This provided our research team with an initial test situation to explore the relative merits of PRS administration. To confirm that responses to the survey provided via PRS were equivalent to online surveys, the research team compared the set of online responses using a Web-based administrative system provided by the University of Washington (Catalyst WebQ) to the responses provided by PRS. Table 9 illustrates the comparison between online and PRS administration for the final three questions of the survey. The consistent trends in response to these questions show that the method of survey administration did not bias student response.

Table 9: PRS vs Web Survey, Questions 14-16

\begin{tabular}{|l|l|c|c|c|}
\cline { 3 - 4 } \multicolumn{2}{c|}{} & \multicolumn{3}{c|}{ Has a librarian ever taught you how to find...? } \\
\cline { 3 - 5 } \multicolumn{2}{c|}{} & Website? & Book? & Magazine article? \\
\hline \multirow{2}{*}{$\begin{array}{l}\text { PRS } \\
\text { N=701 }\end{array}$} & Yes & $61.3 \%$ & $73.3 \%$ & $29.5 \%$ \\
\cline { 2 - 5 } $\begin{array}{l}\text { Web survey } \\
\text { N=146 }\end{array}$ & No & $38.7 \%$ & $26.7 \%$ & $70.5 \%$ \\
\cline { 2 - 5 } & Yes & $65.1 \%$ & $82.2 \%$ & $32.9 \%$ \\
\hline
\end{tabular}

PRS appears to provide reliable data collection for surveys compared to online techniques. Furthermore, it offers the added benefit of automated analytics, instantly available for viewing by the administrator and participants. The PRS systems used in this study permitted teacher-librarians to see student responses aggregated and graphed within moments of student submission, either question-by-question or in summary form. After the survey was administered, TLs could discuss the results with the students, thus creating a boundary object for discussing information behavior concepts, and a rich teaching opportunity. The survey was administered at the class level (25-30 student groups), thus classroom teachers could also participate in this teaching opportunity with the TL.

Finally, the PRS device provided tremendous incentive to participate in the research process. TLs and the research team observed a great deal of interest in the devices and their function, as well as an eagerness on the part of students to engage with the survey and information behavior concepts. Participating in the research process empowered the students, who showed genuine enthusiasm at having their opinions gathered and discussed. In this 
way, data collection for evidence-based practice provided direct benefits to the informants, as well as an incentive to the TLs to act on the data they collected. 


\section{Discussion}

Let us return to the question posed in the introduction to this paper: can we expect secondary students to be able to find a relevant, credible magazine or journal article which supports a given classroom assignment? The findings of this survey suggest that such a search is not likely to be successful. While students appear to have ready access to the web, and show signs that they are more sceptical of digital media than educators and other scholars think they are, this does not mean that they employ the best resources in their research, or that they are facile at retrieving a wide range of resource types. Students report using library portals as a starting point for their search for books (38\%) more often than other types of information resources, but this finding is not to be taken as encouraging. Overall, we found that library portals account for little of the information retrieval activities of students, unless such use is proscribed by the assignment.

The findings related to periodical literature are distressing as they suggest three important and related challenges: 1) students infrequently utilize subscription databases for seeking periodical content; 2) students do not perceive periodicals as trustworthy sources; 3 ) students do not perceive that they have been taught how to access and use periodical literature. As one of the most relevant, scholarly, and timely resources available to libraries, databases are arguably the "must have" portion of any school library collection, right after a solid fiction collection. In many ways, such databases are far superior to the dated (and expensive!) collections of expository non-fiction texts collecting dust on many library shelves. While the teacher-librarians in our study schools heavily emphasized the use of database collections in instruction, it is unclear whether students grasp the advantages they present over other formats. From our survey findings and our prior observations of library activity, a number of questions may be raised: how readily can students distinguish between the "free web" and subscription databases? Do students recognize the diversity and quality of resources present in these databases? How can teacher-librarians, educators, and information providers (such as eLibrary, ProQuest, Grolier, etc.) simplify the process of finding and using vetted periodical literature? While the survey results provide no clear solution to these combined challenges of underutilization, misperception, and inadequate instruction, this paper identifies that these are related problems in need of further research.

One approach to working on these problems is the development of a culture of practitioner research, facilitated by collaborative partnerships with academics and the proliferation of research tools and instruments that can be quickly and easily incorporated into practice. This project attempted to take a step in this direction, by supplying teacherlibrarians with data collection devices that were easy to use and engaging for students. Further research on practitioner methodologies are required to confirm the validity of PRS as

a research instrument. Our initial work in this area may inspire other researcher-practitioner collaborations.

\section{Limitations}

This paper presents data gathered from 939 students in the greater Seattle, Washington (USA) area. The sampling frame is not meant to represent all students, nor even 
the grade nine population of the United States, thus we are cautious in generalizing from these findings. Furthermore, we note that our response rate of participants fell off during the course of the survey, due either to technical problems reported by the teacher-librarians, or through inconsistent administration of the protocol.

While early instrument testing lead to more usable language in survey questions and responses, particularly in terms of format and source choices described, it is unclear how this language may have affected the results. For example, while teacher-librarians use the expression "periodical database" to describe collections of full-text periodical literature and scholarly journal references, we found that students often did not know what this expression meant, or what such resources would contribute to their research. We used the more general term "magazines and newspapers" in place of "periodicals" or "journals". While one may argue these are less accurate or descriptively inclusive terms, the research team erred on the side of participant comprehension.

\section{Conclusions}

Research demonstrates that information literacy skills are becoming increasingly important to life-long learning and success. Students without such skills will be at a disadvantage: they will be unprepared to participate in the media-rich culture that pervades our personal and professional lives. The students in our Grade 9 sample reported that they are at a stage of developing competence in the selection and use of information resources; while there are apparent gaps in their understanding, there are signs that they are accessing a wide range of materials, and engaging in critical assessment of the information they encounter and use in the academic and personal lives.

The findings regarding the use of periodical literature send a challenge to teacherlibrarians, educators, and information providers. Magazines, scholarly journals, and newspapers are some of the most timely and useful content libraries can provide. Our survey finds that subscription databases may be misunderstood, and are certainly underutilized. We need to develop ways of delivering credible, relevant, useful information to students that they can access easily and incorporate readily in their work. Providing high quality resources is simply not enough; as information professional we need to package magazines, journals, and scholarly articles in such a way that the barriers to use are equal to or lower than other resources, and instruct students in the value of these resources relative to books, the Web, and other competing resource formats.

In order to provide the most effective instruction in information and technology literacy, teacher-librarians need to have contextual understanding. That is, they need to have ready knowledge of their student populations, their skills and deficiencies, their access patterns and problem solving strategies. Surveys of the type administered in these six research sites are easily replicable with simple equipment and minimal effort. The resulting data can help "target" interventions and develop school-wide programs for systematically delivering and integrating information skills across the school curriculum. An important methodological contribution of this paper is the introduction of a new survey technology to the arsenal that teacher-librarians already have for gathering evidence to support their work. 
Due to the tremendous complexity of today's information world and variety of information problems students encounter, it is essential that library practice is evidence-based and continually checked against the developing skills, conceptions, and propensities of today's youth.

\section{References}

Agosto, D. E. (2002). A model of young people's decision making in using the Web. Library \& Information Science Research, 24, 311-41.

Bilal, D. (2001). Children's use of Yahooligans! Web Search Engine: II cognitive and physical behaviors on research tasks. Journal of the American Society for Information Science and Technology, 52, 118-36.

British Library \& Joint Information Systems Committee (JISC) (11 January 2008). The information behaviour of the researcher of the future: A Ciber briefing paper. Retrieved 17 January 2008 from http://www.jisc.ac.uk/media/documents/programmes/reppres/gg_final_keynote_11012008.pdf

Fidel, R., Davies, R., Douglass, M., Holder, J., Hopkins, C., Kushner, E., Miyagishina, B., \& Toney, C. (1999). A visit to the information mall: Web searching behavior of high school students. Journal of the American Society for Information Science, 50(1), 24-37.

Fitzgerald, M. A. (2005). Skills for evaluating Web-based information. Paper commissioned for the Internet Credibility and User Symposium. Seattle, WA.

Gordon, C. (1999). Students as authentic researchers: A new prescription for the high school research assignment. School Library Media Research 2. Retrieved 28 January, 2008 from: http://www.ala.org/ala/aasl/aaslpubsandjournals/slmrb/slmrcontents/volume2/gordon_students.cfm

Gross, M., \& Latham, D. (2007). Attaining information literacy: An investigation of the relationship between skill level, self-estimates of skill, and library anxiety. Library \& Information Science Research, 29 (3), 332-353.

Harwood, P. G., \& Asal, V. (2007). Educating the first digital generation. Westport, CT: Praeger.

Heinstrom, J. (2006). Fast Surfing for Availability or Deep Diving Into Quality - Motivation and Information Seeking Among Middle and High School Students. Information Research, 11 (4), 7-17

Herring, J. (2006). A Critical Investigation of Students' and Teachers' Views of the Use of Information Literacy Skills in School Assignments. School Library Media Research, 10, Retrieved 28 January, 2008 from: http://www.ala.org/ala/aasl/aaslpubsandjournals/slmrb/slmrcontents/volume9/ information_literacy.cfm

Israel, B. (5 November 2006). The overconnecteds. New York Times. Retrieved 5 November 2006 from http://www.nytimes.com/2006/11/05/education/edlife/connect.html?

Julien, H. E. (1999). Barriers to Adolescents' Information Seeking for Career Decision Making. Journal of the American Society for Information science, 50(1), 38-48

Kuhlthau, C.C. (1991). Inside the search process: information seeking from the user's perspective. Journal of the American Society for Information Science, 42(5), 361-371.

Kuhlthau, C.C., Caspari, A. K., \& Maniotes, L. K. (2007). Guided inquiry: Learning in the $21^{\text {st }}$ Century. Westport, CT: Libraries Unlimited. 
Levin, D., \& Arafeh, S. (2002). The digital disconnect: The widening gap between Internet-savvy students and their schools. Pew Internet \& American Life Project. Retrieved 17 January 2008 from http://www.pewinternet.org/

Lippincott, J. (2005). Net Generation Students and Libraries. In D. G. Oblinger, and J. L. Oblinger, J. L. (Eds.), Educating the Net Generation. Educause. Retrieved 17 January, 2008 from http://www.educause.edu/content.asp?PAGE_ID=5989\&bhcp=1

McHale, T. (2005). Portrait of a Digital Native. Technology \& Learning, 26(2), 33-34.

Meyers, E. M. (in press). Educating the 'Net Generation: Teachers' perceptions of high school students' information behaviour. Information Research.

Oblinger, D. G. (2003). Boomers, Gen-Xers, and Millennials: Understanding the new students. Educause 38(4), $36-47$.

Prensky, M. (2001a). Digital natives, digital immigrants. On the Horizon, 9(5). Retrieved 17 November 2007 from http://www.marcprensky.com/writing/Prensky\%20$\% 20$ Digital $\% 20$ Natives, $\% 20$ Digital $\% 20$ Immigrants $\% 20-\% 20$ Part $1 . p d f$

Prensky, M. (2001b). Digital natives, digital immigrants. On the Horizon, 9(6). Retrieved 17 November 2007 from http://www.marcprensky.com/writing/Prensky $\% 20$ $\%$ 20Digital $\% 20$ Natives, $\% 20$ Digital $\% 20$ Immigrants $\% 20-\% 20$ Part2.pdf

Schmidt, W. C. (1997). World Wide Web survey research: Benefits, potential problems, and solutions. Behavior Research Methods, Instruments and Computers, 29, 274-279.

Sweeney, R. (2006). Millennial behaviors and demographics. Retrieved 17 November 2008 from http://www.library.njit.edu/staff-folders/sweeney/Millennials/Millennial-Behaviors.doc

Williamson, K., McGregor, J., Archibald, A., \& Sullivan, J. (2007). Information seeking and use by secondary students: The link between good practice and the avoidance of plagiarism. School Library Media Research, 10, accessed January 28, 2008, from: http://www.ala.org/ala/aasl/aaslpubsandjournals/slmrb/slmrcontents/volume10/williamson_information seeking.cfm

\section{About the Authors:}

Eric Meyers is a doctoral candidate at the University of Washington Information School, where he studies school library programs and youth information behavior in formal and informal contexts. His dissertation will explore how children solve information problems individually and in small groups. Eric holds Masters Degrees in Information and Education from the University of Michigan and Stanford University respectively.

Mike Eisenberg is Professor and Dean Emeritus at the University of Washington Information School. Mike focuses on the use of information and information technology by individuals and organizations to meet their information needs and manage their information more effectively and efficiently. He is internationally known for his innovative approach to information problem-solving and technology in learning and teaching: the Big6.

\section{Statement of Originality}

This statement certifies that the paper above is based upon original research undertaken by the author and that the paper was conceived and written by the author(s) alone and has not been published elsewhere. All information and ideas from others is referenced. 



\section{Appendix}

\section{Student Survey Instrument}

Procedure: Allow teacher librarian to administer the survey to $9^{\text {th }}$ grade students within the constraints of a given school context. Teacher Librarians administered the survey using the Personal Response System technology and equipment supplied by the Small Schools Project.

Script: Thank you for agreeing to participate in this research study. Please use the remote control like device to indicate your responses to the questions that will appear on the screen as I read them aloud. Only one response will be registered per question regardless of how many times you depress a button. You can change your response in the time allotted simply by pressing a different button that reflects your new response. Participation is voluntary. You do not have to respond to any of the questions at all. Your responses will be anonymous; we will not know how each of you individually responded nor whether you responded. Your grade for this class will not be affected by your responses.

Do any of you have any questions before we begin?

\section{Questions:}

1. Do you have internet access at home?
a. Yes
b. No

2. Other than home, where else are you most likely to access the internet?
a. School
b. Public library
c. Coffee shop
d. Friend's house
e. Other

3. How often do you visit the school library?
a. At least once per week
b. About 2-3 times per month
c. About once per month
d. About 2-3 times per year
e. About once per year or less

4. How often do you visit the public library?
a. At least once per week
b. About 2-3 times per month
c. About once per month
d. About 2-3 times per year
e. About once per year or less

5. Do you ever go to the library to see your friends?
a. Yes
b. No

6. Do you ever go to the library to read?
a. Yes
b. No

7. Where would you go to find a website?
a. Google, Yahoo, MSN or other search engine
b. Digital Learning Commons
c. Library website
d. Other 
8. Where would you go to search for a book?
a. Google, Yahoo, MSN or other search engine
b. Library website
c. Amazon.com
d. Bookstore or newsstand
e. Other

9. Where would you go to search for a magazine article?
a. Google, Yahoo, MSN or other search engine
b. Digital Learning Commons
c. Library website
d. Bookstore or newsstand
e. Other

10. Which information sources do you use the most to finish your homework?
a. Websites
b. Books
c. Magazines or newspapers
d. Radio, television or movies
e. Friends or family members

11. Which information source do you trust the most?
a. Websites
b. Books
c. Magazines or newspapers
d. Radio, television or movies
e. Friends or family members

12. Which information source do you trust the least?
a. Websites
b. Books
c. Magazines or newspapers
d. Radio, television or movies
e. Friends or family members

13. Where do you get most of your news?
a. Websites
b. Magazines or newspapers
c. Radio, television or movies
d. Friends or family members

14. Has a school librarian ever taught you how to find a website?
a. Yes
b. No

15. Has a school librarian ever taught you how to find a book?
a. Yes
b. No

16. Has a school librarian ever taught you how to find a magazine article?
a. Yes
b. No 